\title{
HISTÓRIA E SEU ENSINO NO ESPÍRITO SANTO: entre rupturas, permanências e resistências
}

\author{
Regina Celi Frechiani Bitte \\ Sonia Maria dos Santos
}

\section{Resumo}

O presente artigo tem por objeto de análise a história do ensino de história com recorte temporal entre os anos de 1970 a 1990 no estado do Espírito Santo (ES) e objetiva identificar e compreender as rupturas e permanências neste ensino nas Propostas Curriculares do estado. Assim, buscamos entabular um diálogo com a autores que abordam o ensino de História no Brasil como Bittencourt (2004, 2010) e Fonseca (2012), bem como com teses e dissertações da Biblioteca da UFES e do IFES de Vitória, no ES. O estudo aponta para nuanças nas Propostas Curriculares do ES em consonância com a conjuntura maior no Brasil. Sinaliza, também, a resistência dos professores frente aos documentos normatizadores produzidos na noosfera.

Palavras-chave: ensino de História; Espírito Santo; História ensinada.

\section{HISTORY AND ITS TEACHING IN ESPÍRITO SANTO: between ruptures, permanences and resistance}

\begin{abstract}
This article aims to analyze the history of history teaching with a time frame between the years 1970 and 1990 in the state of Espírito Santo (ES) and aims to identify and understand the ruptures and permanencies in this teaching in the State's Curriculum Proposals. Thus, we seek to establish a dialogue with authors who address the teaching of History in Brazil as Bittencourt (2004, 2010) and Fonseca (2012), as well as a survey of theses and dissertations at the UFES and IFES Library in Vitória (ES). The study points to nuances in the ES Curriculum Proposals in line with the greater situation in Brazil. It also signals the resistance of teachers to normative documents produced in the noosphere.
\end{abstract}

Keywords: History teaching; Espírito Santo; History taught.

\section{LA HISTORIA Y SU ENSEÑANZA EN ESPÍRITO SANTO: entre rupturas, permanencias y resistencias}

Resumen

Este artículo tiene como objetivo analizar la historia de la enseñanza de la historia con un marco temporal entre los años 1970 y 1990 en el estado de Espírito Santo (ES) y tiene como objetivo identificar y comprender las rupturas y permanencias de esta enseñanza en las Propuestas Curriculares del Estado. Así, buscamos establecer un diálogo con autores que abordan la enseñanza de la Historia en Brasil como Bittencourt $(2004,2010)$ y Fonseca (2012), así como un relevamiento de tesis y disertaciones en la Biblioteca UFES e IFES en Vitória (ES). El estudio apunta a matices en las Propuestas Curriculares de ES en línea con la situación mayor en Brasil. También señala la resistencia de los profesores a los documentos normativos producidos en la noosfera.

Palabras clave: enseñanza de la Historia; Espírito Santo; se enseña Historia. 


\section{INTRODUÇÃO}

O presente artigo tem por objeto de análise a história do ensino de História, com ênfase nos caminhos percorridos nas três últimas décadas do século XX, envoltas em ditadura, reabertura política e novas tendências teóricas e metodológicas. Para tanto, objetiva-se identificar os caminhos percorridos pela História e seu ensino, no estado do Espírito Santo (ES), buscando compreender as rupturas, mudanças e permanências, neste ensino, materializadas nas Propostas Curriculares, aprovadas e implementadas em terras capixabas.

$\mathrm{Na}$ perseguição do objetivo, procedeu-se a uma incursão na bibliografia referente aos percursos do ensino de História no Brasil. Especificamente no que se refere ao estado do Espírito Santo, o rastreamento bibliográfico realizado teve como foco de buscas os repositórios de teses e dissertações das Bibliotecas da Universidade Federal do Espírito Santo (UFES) e do Instituto Federal de Ensino Superior (IFES), de Vitória (ES).

No site do repositório de teses e dissertações da UFES, a busca realizada utilizando como descritor o termo "história da História ensinada" possibilitou a localização de oito trabalhos. Ampliando as buscas, utilizamos o descritor "ensino de História", localizamos noventa títulos, entre teses, dissertações, livros, folhetos, folhas soltas, eventos. Após a leitura dos resumos, constatamos que 22 trabalhos se referiam ao ensino de História.

No repositório de teses e dissertações do IFES, também utilizamos os descritores de busca: "história da História ensinada", sendo encontrados três trabalhos. Após leitura dos resumos, constatamos que apenas um se referia ao ensino de História. Ao ampliarmos os critérios de busca, utilizando o descritor "ensino de História", foram encontrados 46 trabalhos. Após leitura dos resumos, observamos que quatro trabalhos se referiam especificamente ao ensino de História.

Após a realização de criteriosas leituras dos resumos dos trabalhos encontrados que se referiam ao ensino de História ou história da História ensinada, com foco em nossa temática de pesquisa, foi possível identificar e selecionar os trabalhos de: Luiz (2015), França (2020) e Scalzer (2007), por estarem intimamente relacionados ao nosso tema, espaço e tempo, compondo o corpus teórico para a produção desse texto.

\section{OS CAMINHOS PERCORRIDOS PELA HISTÓRIA E SEU ENSINO: RUPTURAS E PERMANÊNCIAS}

Conforme bem salientam Costa e Oliveira (2007) as universidades no Brasil pouco se voltaram para as questões do ensino. No que se refere ao ensino de História, não foi diferente. Este foi visto, até a década de 1960, como área de formação e não como objeto de pesquisa. Tal visão deve-se, em parte, à separação entre o ensino e a pesquisa, que marcou o surgimento das licenciaturas, no nosso caso específico, a de História. Assim, caberiam às disciplinas denominadas de pedagógicas as questões de ensino e de ciência de referência — os conhecimentos históricos.

Essa separação entre ensino e pesquisa foi ainda mais acirrada com a criação dos cursos de pós-graduação, no Brasil, depois das reformas de 1970, principalmente a Lei n. 5692/71. As questões do ensino se restringiram aos Programas de Pós-Graduação em Educação, com a possibilidade de pesquisas em temas variados, mas, no que se refere a o quê e como ensinar, isso ficou relegado a um segundo plano. (COSTA, OLIVEIRA, 2007).

A história do ensino de História só passou a ser considerada como objeto de pesquisa a partir da década de 1980, quando ocorreu uma ampliação dos cursos de pós-graduação nas universidades brasileiras. Registrou-se, a partir de então, uma permanência do tema dentre as 
investigações da área, nos novos espaços criados, tais como os Anais dos encontros sobre o Ensino de História, Perspectivas do Ensino de História, Encontro Nacional de Pesquisadores do Ensino de História e Simpósios da Associação Nacional de Professores Universitários de História (ANPUH) (BITTENCOURT, 2011).

Não obstante, ao considerarmos aspectos históricos precedentes ao nosso marco temporal, observamos que a década de 1950 foi um período de intensos debates e embates em torno da elaboração da Lei n. 4024/61 (Lei de Diretrizes e Bases da Educação Nacional / LDB). Havia, então, uma intensa discussão entre intelectuais e educadores acerca da criação dos Estudos Sociais, que substituiriam a História e a Geografia nos currículos do nível secundário.

Os Estudos Sociais eram uma das preferências de intelectuais ligados à Escola Nova, como o professor Delgado de Carvalho, pertencente aos quadros do Colégio Pedro II e do Instituto de Educação, muito próximo ao círculo de Anísio Teixeira nas esferas de poder do Instituto Nacional de Ensino e Pesquisa (Inep). Em defesa dessa nova disciplina, Delgado de Carvalho escreveu sobre a trajetória da História e da Geografia em currículos nacionais e internacionais (BITENCOURT, 2011).

As mudanças ocorridas no ensino de Estudos Sociais, defendidas por Delgado de Carvalho, fizeram-se na superação do entendimento de que a criança possuía a sua configuração mental limitada e submetida à mera memorização dos conhecimentos; bem como na superação da concepção de que o professor seria um mero reprodutor de modelos de técnicas e métodos de ensino; e, também, no entendimento de que o conhecimento fosse especializado e fragmentado. Assim, o diálogo com a Psicologia do Desenvolvimento da Criança fez emergirem novos paradigmas pedagógicos centrados nas aprendizagens, evidenciando a preocupação de como as crianças aprendem (FRANÇA, 2013).

Com a ditadura militar, os ideais pedagógicos centrados nas aprendizagens das crianças e apregoados pelos Estudos Sociais, foram abandonados. Nova roupagem foi criada, para formar não crianças pensantes, críticas, mas, sim, crianças obedientes aos ditames do Estado. $\mathrm{O}$ aluno não deveria discutir, mas se ajustar. Nesse sentido, na década de 1970, a ênfase deu-se, predominantemente, nos aspectos didáticos e metodológicos relacionados às tecnologias de ensino.

Com a implantação da Lei n. 5.692/71, o ensino de História ficou desfavorecido, pois se instituiu um currículo tecnicista, com o objetivo de atender a demanda profissionalizante, sem ter apoio estrutural e financeiro, em detrimento do caráter científico que o antigo ensino possuía. Bittencourt (2010) avalia assim currículo do período:

[...] um currículo de caráter científico, mas entendido em sua formulação apenas tecnicista, consegue se impor e as áreas de humanas passam por um amplo processo de descaracterização e perda de status. A História do Brasil se mescla a estudos de Geografia, Educação Moral e Cívica (EMC) e Organização Social e Política do Brasil (OSPB), formando um amálgama de conhecimentos superficiais e sem base científica. (BITTENCOURT, 2010, p. 197).

As disciplinas de História e a Geografia se fundiram em Estudos Sociais, com o objetivo de sintetizar o ensino sobre a sociedade e diminuir o núcleo de docentes e, ainda, competir com os conteúdos dogmáticos trabalhados nas aulas de EMC e OSPB. (BITTENCOURT, 2004).

As mudanças que ocorreram foram relativas aos métodos e técnicas de ensino que visavam a adequar-se a determinado e reduzido conhecimento histórico. Em sua essência, os conteúdos não foram alterados, mas simplificados e resumidos. Não havia nenhuma crítica ao predomínio de uma história eurocêntrica. A "genealogia da nação" (BITTENCOURT, 2004, p. 83) encontrava-se na Europa, e o mundo brasileiro era branco e cristão. 
No estado do Espírito Santo, a Lei n. 5692/71 se fez presente nas propostas curriculares elaboradas, demonstrando a força do Estado ditatorial. No entanto, apesar de toda repressão, é possível perceber matizes diferenciados do proposto na Lei. Em 1972, na gestão do secretário de educação e cultura Aci Nigri do Carmo, foi apresentado o Plano de Implantação do então Ensino de $1^{\circ}$ e $2^{\circ}$ Graus, elaborado pela Comissão Estadual de Planejamento e Assessoria Educacional com as metas previstas para a política educacional de desenvolvimento do ensino daqueles níveis em consonância com as diretrizes da Lei n. 5.692/71.

Conforme citado por França (2013), o referido Plano de Implantação ressaltava: a) extensão da oportunidade de educação ao maior número possível de indivíduos; b) aumento da produtividade do ensino; c) ajustamento dos objetivos e conteúdos dos graus de ensino às necessidades do desenvolvimento socioeconômico do Estado, mediante um novo tipo de formação do educando.

Conforme salienta França (2013), a Comissão Estadual de Planejamento e Assessoria Educacional estabeleceu como prioridade a implantação de 34 Escolas Polivalentes e um Colégio Compreensivo pelo Programa de Expansão e Melhoria do Ensino (Premen). Naquele momento, foi elaborada a proposta curricular dos Colégios Polivalentes do Espírito Santo, priorizando-se a estruturação dos cursos profissionalizantes.

No decorrer do Governo de Élcio Álvares, as referidas reformas no currículo educacional do estado do Espírito Santo foram sequenciadas. Em decorrência e sob a gestão do Secretário de Educação e Cultura Alberto Stange Júnior, a Equipe de Currículo do então Segundo Grau, chefiada pela Professora Evany Valadares Borges, iniciou o trabalho de reformulação da proposta curricular do antigo $2^{\circ} \mathrm{Grau}$, instituída em 1974 e publicada em 1975. Nela, foram priorizados os princípios da eficiência e a produtividade. Caberia àquele nível de ensino preparar o adolescente para participar de forma eficiente no desenvolvimento brasileiro. (FRANÇA, 2013).

Os princípios norteadores da proposta curricular do então $2^{\circ}$ grau foram justificados tendo por base as diretrizes da Lei n. 5.692/71 e os impactos da implantação de Grandes Projetos Industriais: a Usina de Pelotização da Companhia Vale do Rio Doce (CVRD), a Usina Siderúrgica de Tubarão (CST), a Usina de Pelotização Samarco e as indústrias siderúrgicas com terminais portuários. A ideia de desenvolvimento econômico do estado do Espírito Santo estava associada à ideia de grandes projetos econômicos do governo brasileiro, que circulou intensamente por meio de jornais e revistas da época, por exemplo, a Revista Capixaba (FRANÇA, 2013).

Assim, ressalta-se, no entanto, que anteriormente à Proposta curricular para o então $2^{\circ}$ grau, no estado do Espírito Santo tivemos outras duas propostas. A do ensino primário e, também, a do ensino do primeiro grau, hoje séries finais do ensino fundamental, com duas versões: uma experimental de 1973 e a outra versão final de 1974. O que podemos inferir dessas propostas curriculares sobre o ensino de História?

Na versão da proposta curricular de 1973 , voltada para a $1^{a}$ a $4^{a}$ série do $1^{\circ}$ Grau, hoje séries iniciais do ensino fundamental, prevaleceram os Estudos Sociais. No entanto, foram apresentados como uma disciplina escolar, denominada Integração Social, e não como uma área de integração de saberes, destoando dos projetos de ensino de Estudos Sociais propostos, principalmente, por Delgado Carvalho, que era, conforme já mencionamos anteriormente, a formação integral do ser humano.

A proposta curricular de 1973 sofreu alterações em 1974. Os trabalhos de reformulação curricular foram coordenados por uma equipe formada pelas professoras Déa Martins Galvêas Loureiro, Evany Valadares Borges, Maria da Penha D’Avila Couto e Eliana Umbelino de Souza Albernaz (coordenadora da equipe), que atuaram como assessoras da área de Integração Social (Estudos Sociais). Para assegurar o trabalho de reformulação da proposta curricular, criou-se a 
equipe técnica de Divisão de Currículo e Supervisão, sob a coordenação da professora Dora Cortat Simonetti. (FRANÇA, 2013)

Em decorrência da referida reforma, a proposta curricular estadual de 1974 se organizou da seguinte forma: da $1^{\mathrm{a}}$ a $4^{\mathrm{a}}$ série, o ensino de História e Geografia resultou na disciplina conhecida como Integração Social. Para as $5^{a}$ e $6^{a}$ séries, resultou nos Estudos Sociais, com as aulas ministradas por apenas um professor, de cultura geral. Para as turmas de $7^{\mathrm{a}}$ e $8^{\mathrm{a}}$ séries, com um professor especialista para cada disciplina. A proposta curricular propunha, ainda o ensino de Educação Moral e Cívica (EMC), a ser trabalhado na $7^{a}$ série e o de Organização Política e Social Brasileira (OSPB), na $8^{a}$ série. Em consonância com a Resolução n. 8, do Conselho Federal de Educação, de 9/8/72, a proposta curricular acatou a determinação de que os conteúdos mínimos da disciplina História deveriam estar relacionados à História Antiga, Medieval, Moderna, Contemporânea e do Brasil. (FRANÇA, 2013).

No que tange à disciplina de Estudos Sociais, a ser trabalhada na $5^{a}$ e $6^{a}$ séries, os professores elaboradores fizeram a divisão por objetivos, sugestões de conteúdos, e eixo-norteador: atitudes sociais, o trabalho na vida da comunidade, habilidades específicas, aspectos geográficos e históricos (do Brasil, na $5^{\mathrm{a}}$ série; das Regiões do Brasil, na $6^{\mathrm{a}}$ série). Já para a $7^{\mathrm{a}}$ série, os objetivos e sugestões de conteúdos tiveram como referência os eixos-norteadores, atitudes sociais e habilidades específicas; História Geral - objetivos e sugestões de conteúdos; Geografia Geral - conhecimentos, objetivos e sugestões de conteúdos. Para a $8^{a}$ série, os objetivos e sugestões de conteúdos, seguiram também os eixos-norteadores de atitudes sociais e habilidades específicas; História Geral conhecimentos, objetivos e sugestões de conteúdos; Geografia Geral - conhecimentos, objetivos e sugestões de conteúdos. (FRANÇA, 2013).

Ainda, no que se refere à Proposta estadual de 1974, Luiz (2015) observa que nas $5^{a}$ e $6^{a}$ séries, a História baseia-se na cronologia tradicional. Nas $7^{\mathrm{a}}$ e $8^{\mathrm{a}}$ séries, no que tange a objetivos e sugestões, observa-se o trabalho de propostas de História e de Geografia, com predomínio do modelo quadripartite francês, em conformidade com os Cadernos MEC para a disciplina História Geral. O que distancia o conteúdo da Proposta em relação a esse documento é o aspecto pedagógico. Enquanto o Caderno do MEC pautava-se por uma visão tradicional, a Proposta privilegiava características do método ativo.

Destacamos que a reforma da proposta curricular estadual, voltada para o $1^{\circ}$ Grau (hoje ensino fundamental), determinou que os conteúdos de História e Geografia, a serem trabalhados nas $7^{a}$ e $8^{a}$ séries seriam ministrados por professores com formação específica na área de conhecimento. Assim, em relação aos conteúdos trabalhados, apesar de se garantir a concepção de integração limitada às matérias de Geografia e História, garantiram-se, também, os conteúdos específicos de cada área. Por outro lado, os conteúdos programáticos continuaram sendo trabalhados a partir da genealogia da nação europeia.

Conforme ressalta Luiz (2015), na narrativa dos professores entrevistados para compor o corpus documental de sua tese de doutorado, havia uma forte resistência em relação à atuação de um único docente para trabalhar os Estudos Sociais nas $5^{a}$ e $6^{a}$ séries. Questionavam como um professor com formação em uma área poderia ministrar outra área para a qual ele não fora habilitado.

Dessa forma, o Programa de Estudos Sociais, seja como Integração Social para as quatro primeiras séries ou como Estudos Sociais e Organização Social e Política Brasileira, da $5^{\mathrm{a}}$ a $8^{\mathrm{a}}$ séries, compreende as chamadas "Atitudes Sociais", isto é, se pautava na justificativa da busca pela participação adequada do indivíduo na vida em grupo (LUIZ, 2015), salientando ser o mínimo que se poderia esperar de um cidadão em relação às questões cívicas e sociais para com a sua pátria. 
Em relação à Reforma do $2^{\circ}$ Grau (hoje ensino médio), com o objetivo de organizar o currículo do estado do Espírito Santo, tendo como referência as diretrizes da Lei n. 5692/71, priorizou-se a oferta de habilitações profissionais em nível de $2^{\circ}$ grau, com ênfase na formação para o trabalho e preparação e exercício consciente da cidadania. (FRANÇA, 2013).

Analisando a Proposta curricular para o $2^{\circ}$ Grau, de 1975, e os Cadernos do MEC: História Geral, Luiz (2015) ressalta o predomínio da História eurocêntrica. Segundo a autora, a História do Brasil era tangenciada, ou melhor, só era mencionada quando se relacionasse diretamente com os conteúdos da História do Ocidente, constituindo-se, assim, como apêndice da História Ocidental.

Ainda segundo Luiz (2015), a Proposta Curricular de Segundo Grau para os Estudos Sociais, sinaliza para a junção do primário com o ginasial, em uma substituição da estrutura dualista por um sistema único que, em última instância, visava à escola voltada para a educação básica geral, bem como à preparação para o trabalho, reafirmando o princípio da integração, estabelecido pela Lei n. 5.692/71. O princípio de integração se corporifica na continuidade e na terminalidade.

Outro documento que apresenta ricas contribuições para se compreender o ensino de História no Espírito Santo é "Orientações Curriculares para a Disciplina de Estudos Sociais", publicado em 1978 com o objetivo de orientar os professores na aplicação da Proposta Curricular de 1974.

Conforme ressalta Luiz,

[...] enquanto a Proposta Curricular de $1^{\mathrm{a}}$ a $8^{\mathrm{a}}$ série (1974), no que se refere ao método, evidencia vinculações ao método ativo escolanovista, com ênfase nos interesses dos alunos e no desenvolvimento e aperfeiçoamento de técnicas de ensino, nas Orientações, por outro lado, predomina o tecnicismo, com a proposta de repetição de atividades e exercícios de treinamento. Pretendia-se, dessa maneira, que o indivíduo absorvesse temas sociais sem reflexão crítica. Métodos e técnicas, pautados em categorias como racionalidade, funcionalidade e eficiência, cumpririam a função de "neutralizar" o conteúdo cultural e político. (LUIZ, 2015, p. 160).

Ao se referir à Proposta de 1974 e às Orientações Curriculares para a disciplina de Estudos Sociais, a autora destaca o distanciamento, que estas tiveram, dos Cadernos MEC: História Geral e do Guia, também elaborado pelo MEC com o objetivo de auxiliar, nortear a concepção de História. Estes últimos mesclam, em seu texto, elementos da perspectiva tradicional e aspectos relacionados com a História Nova, ao enfatizar o trabalho com fontes diversificadas; interface da História global/local; atribuições do aluno como produtor da História e a interdisciplinaridade sugerida em algumas atividades.

Essa presença da Nova História é um reflexo das mudanças e reformulações, ocorridas nas últimas três décadas do século XX, tanto no que se refere à produção do conhecimento histórico, quanto no ensino de História. Concordamos com Fernandes (2005) que tal processo de mudanças associa-se às novas tendências teóricas e metodológicas, calcadas na Nouvelle Histoire e na História Social Inglesa, que elencaram, como objeto de estudo, "[...] temas relativos ao cotidiano, à vida privada, às mentalidades coletivas, ao imaginário e às representações sociais de segmentos até então desprezados pela dita 'História Oficial”' (FERNANDES, 2005, p. 121). Essas tendências se fizeram refletir nas reformas educacionais, bem como nos materiais didáticos produzidos no período.

A partir do exposto, com nuanças, em relação a metodologia e a concepção de História, comungamos com França (2013) e Luiz (2015) a concepção de que as propostas curriculares para os $1^{\circ}$ e $2^{\circ}$ Graus tiveram como prioridade a formação do aluno para o trabalho. No caso da organização do ensino de $2^{\circ} \mathrm{Grau}$, foram implantados os cursos de habilitação profissional, com a 
preparação de mão de obra especializada, para atender as exigências do momento histórico em que vivia o Estado do Espírito Santo.

Entretanto, o quadro que foi gestado na educação, no decorrer dos anos de 1970, no Brasil, possibilitou a aproximação entre a academia e os demais níveis de ensino, com um objetivo em comum: a qualidade do ensino e o seu direcionamento. Em decorrência, as discussões que envolveram todos os níveis de ensino voltaram seus olhares para a elaboração de um projeto que recuperasse a especificidade teórica e metodológica, tanto da Geografia, quanto da História, e se voltasse para a formação da consciência crítica do aluno.

Os governos militares impuseram a repressão e a desmobilização. Em alguns momentos, motivados não por um planejamento anterior e explícito dos militares, mas pela coerência e resistência dos profissionais da educação, dentre eles, os de História. As imposições e controles a estes profissionais possibilitaram, na contramão do processo histórico, a construção de novos caminhos para a História e seu ensino.

Como bem nos lembra Gatti Jr. (2010), as mudanças ocorridas no ensino de História não resultam única e exclusivamente de questões legais e governamentais, mas, sim, respondem a pressões exercidas pelo movimento de docentes de História, o que, após o término do período da ditadura militar, em 1985, fomentou alterações nos programas de ensino e nos livros didáticos de História.

Em decorrência e, também, no contexto da ampliação dos cursos de pós-graduação das universidades brasileiras, na década de 1980, ocorre a retomada de pesquisas sobre a história do ensino de História. O ensino da História, incluindo as análises sob perspectivas históricas, passou a fazer parte das pesquisas formuladas em meio aos debates sobre as reformas curriculares que, então, ocorriam em vários estados do país. Dentre essas pesquisas, destaca-se a realizada por Bittencourt (1998), no período compreendido entre 1985 e 1995, com ênfase na diversidade de abordagens historiográficas e teórico-metodológicas em propostas curriculares de História.

Conforme Bittencourt (1998), as propostas curriculares apresentavam matizes diferentes nos textos produzidos, principalmente, na sua confecção e apresentação aos professores, no que tange aos conteúdos elencados e às metodologias de ensino. Logo, na apresentação das propostas, a autora faz a ressalva em relação à superação do modelo tecnicista presente nos anos de 1970, em que se privilegiavam objetivos, conteúdos e as questões didáticas. A autora aponta como inovação a preocupação das propostas com a História ensinada, voltada para a concepção de ensino de História que possa contribuir para a formação de cidadãos críticos. Nesse sentido, defende a proposta de se trabalhar a formação do aluno para que o mesmo tenha condições de compreender e transformar a realidade em que vive. Em outras palavras, sentir-se sujeito histórico.

A autora destaca, ainda, que apesar das propostas curriculares afirmarem que existe um diálogo com as novas tendências historiográficas, o fosso continua entre produção científica e saber escolar. E assevera que o saber escolar apresentado nas propostas curriculares mais parece uma vulgarização e uma simplificação do saber científico a ser transformado no saber a ser ensinado. $O$ papel desempenhado pelo professor, na mediação desses saberes, parece não ser considerado na História ensinada.

Para Bittencourt (1998), as propostas curriculares relegaram, na sua construção, aspectos importantes da formação do professor de História, bem como suas condições reais de trabalho para desenvolver o ensino. Teoriza-se um modelo de professor ideal para uma escola, também, ideal e não se leva em consideração o real cotidiano do professor e da escola.

Assim, ao final da década de 1980, intensificam-se os debates em relação às pesquisas, ao ensino e às reformas curriculares. São enfatizados, dentro e fora da academia, os debates sobre a formação e a prática dos professores. 
Destacam-se, também, os novos espaços criados para se debater sobre o ensino de História, como exemplo, no ano de 1988, a realização do I Seminário Perspectiva do Ensino de História, organizado pela prof ${ }^{a}$. Dr ${ }^{a}$. Elza Nadai, professora de Prática de Ensino de História da Universidade de São Paulo (USP). Esse seminário tinha, como um dos seus principais objetivos, ouvir e refletir sobre uma demanda, sempre crescente entre os professores, acerca dos caminhos que estavam se delineando para o ensino de História (COSTA, OLIVEIRA, 2007).

Os anos de 1990 foram expressivos para a ampliação dos debates, não só para o ensino de História, mas para toda educação. O período foi marcado como momento da organização mais sistemática, da escrita das Diretrizes Curriculares Nacionais dos Cursos Superiores de História (1999), da Lei n. 9394/96 (Lei de Diretrizes e Bases da Educação Nacional), dos Parâmetros Curriculares Nacionais (PCNs) para o ensino fundamental e médio (a partir de 1997). Despontaram, também, novos espaços para os debates, a exemplo da realização do I Encontro Nacional de Pesquisadores do Ensino de História (ENPEH), ocorrido em 1993, na Universidade Federal de Uberlândia.

Até o ano de 1996 vigoraram, nos ensinos de $1^{\circ}$ e $2^{\circ}$ graus, os preceitos da Lei n. 5692/71, quando o ensino de $1^{\circ}$ Grau foi estruturado com oito anos de escolaridade e obrigatório; e o de $2^{\circ}$ Grau, com três anos, porém não contemplando a obrigatoriedade. Essa mesma lei prescrevia, em relação ao currículo, uma parte comum obrigatória, para ambos os níveis de ensino, e outra diversificada, com a finalidade de contemplar realidades locais. Prescrevia, ainda, que seria de competência do Estado a organização de propostas curriculares como parâmetros para as escolas estaduais e municipais. Conforme Fonseca (1993), essas propostas foram reformuladas, na década de 1980, levando em consideração as diversas áreas de conhecimento.

Esse quadro no ensino sofre alterações com a promulgação da nova Lei de Diretrizes e Bases da Educação Nacional (Lei n. 9394/96), que veio ratificar a Lei n. 5692/71, no que se refere à obrigatoriedade e ao currículo da educação básica. Segundo a Lei, é dever do Estado garantir o ensino fundamental ( $1^{\circ}$ grau) obrigatório e gratuito e, acrescente-se, a progressiva extensão, destes últimos, ao ensino médio ( $2^{\circ}$ grau).

Em relação ao currículo, a nova LDB n. 9394/96, em consonância com o Art. 210 da Constituição Federal do Brasil de 1988, preceitua, em seu Art. 26, que:

[...] os currículos da educação infantil, do ensino fundamental e do ensino médio devem ter base nacional comum, a ser complementada, em cada sistema de ensino e em cada estabelecimento escolar, por uma parte diversificada, exigida pelas características regionais e locais da sociedade, da cultura, da economia e dos educandos (BRASIL, 1996).

Com a aprovação da LDB n. 9394/96, o Ministério da Educação (MEC) estende seus tentáculos em todo sistema educacional brasileiro, conforme explicita o seu Art. 9": "A União incumbir-se-á de: I - elaborar o Plano Nacional de Educação, em colaboração com os Estados, o Distrito Federal e os Municípios".

Em decorrência e ancorado na prescrição do Artigo acima, na esteira das políticas públicas, foi criado o Plano Decenal de Educação (1993-2003); o Fundo de Manutenção e Desenvolvimento do Ensino Fundamental e Valorização do Magistério (Fundef); a Avaliação da Educação Básica (SAEB); o Exame Nacional do Ensino Médio (Enem); e as Diretrizes Nacionais para a Formação de Professores, entre outros. Nesse contexto é que foram elaborados os Parâmetros Curriculares Nacionais (PCNs), com contribuições das propostas curriculares organizadas no decorrer dos anos de 1980 e início dos anos de 1990. 
Se, por um lado, as propostas curriculares apresentavam matizes diferentes nos textos produzidos, por outro lado, conforme destaca Bittencourt (2004), algumas características eram comuns a elas, tais como: alterações nas formulações técnicas dos textos curriculares, que passaram a apresentar fundamentações sobre o conhecimento histórico e sobre os demais tópicos da disciplina; preocupação com a implementação e a busca por legitimidade junto ao corpo docente; redefinição do papel do professor, com vista a maior autonomia no trabalho pedagógico; apresentação mais detalhada dos pressupostos teóricos e metodológicos do conhecimento histórico; fundamentação pedagógica a partir dos referenciais do construtivismo, em que o aluno é o sujeito do processo de aprendizagem; aceitação de que o aluno possui um conhecimento prévio e que deve ser integrado ao processo de aprendizagem; e introdução dos estudos históricos a partir das séries iniciais do ensino fundamental. A referida autora ressalta que parte dessas características foram incorporadas pelos PCNs.

Dessa forma, os PCNs de História, em suas propostas para os alunos de $5^{\mathrm{a}}$ a $8^{\mathrm{a}}$ série, vão manter a caracterização disciplinar, ministrada por um professor especialista. Assim, os fundamentos teóricos e metodológicos têm como objetivos explicitar os pressupostos da História a ser ensinada, com vistas a situar a produção bibliográfica em que as propostas foram produzidas. A maioria baseou-se na História social ou sociocultural, pois contemplam conceitos e bibliografia que vão ao encontro dessas tendências teóricas. Os conceitos são considerados a base para o conhecimento histórico, com coerência entre os objetivos da disciplina e os fundamentos historiográficos e pedagógicos, sendo elencados como conceitos fundamentais os de cultura, trabalho, organização social, relações de poder e representações. (BITTENCOURT, 2004)

Observa-se, segundo os PCNs de História, uma atribuição de relevância para o domínio dos conceitos, voltados para as séries finais do ensino fundamental. No que se refere aos conteúdos, não existe uma seleção predeterminada para cada uma das séries, sendo que as propostas se baseiam em eixos temáticos ou temas geradores. Conforme salienta Bittencourt (2004), recorre-se aos temas e aos conceitos devido à impossibilidade do estudo de toda a História da humanidade, o que não significa, no entanto, que não haja uma preocupação de totalidade em sua abordagem.

Os PCNs de História, para o ensino médio, procuraram articular a formação para a cidadania e os conceitos históricos básicos. Assim como nas séries finais, permaneceram a organização dos conteúdos por temas geradores e os fundamentos teóricos, apoiados na História social e cultural. Foram incorporadas ao texto contribuições dos historiadores E. Thompson e Ginzburg, bem como dos da nova História francesa (BITTENCOURT, 2004).

Além das questões de conteúdos e questões teóricas e metodológicas, presentes nos PCNs, no que tange à área de História, Bittencourt (2004) destaca o papel das disciplinas na constituição dos saberes escolares. Como os PCNs são apresentados por "áreas de conhecimento" e, nesse sentido, a História, ao lado da Geografia, da Sociologia, da Antropologia e da Filosofia passam a constituir-se como parte integrante das denominadas "Ciências humanas e suas tecnologias", a autora ressalta a possibilidade de acarretar a perda de conceitos, informações e métodos que compõem cada uma das disciplinas. Nesse sentido, a autora chama a atenção para os reflexos dessa organização, a médio e longo prazo, na formação docente.

Especificamente no que tange ao estado do Espírito Santo, observa-se que as propostas curriculares pensadas e implementadas na década de 1990 vão dialogar com esse contexto macro dos PCNs.

Em relação à década de 1990, a dissertação de mestrado de Scalzer (2007) aborda os PCNs em sua dimensão curricular e de política pública, ao discuti-los enquanto estratégia da noosfera que tem por objetivo interferir de forma incisiva na (con)formação cultural da população. Assim, 
baseia-se em uma abordagem que parte das categorias de análise "leitura", "apropriação", "representação" e "prática" de Chartier (1990); e "táticas" e "estratégias" de Certeau (2004). A autora investigou a suposta influência dos PCNs no discurso e prática pedagógica dos professores, com o intuito de compreender as estratégias utilizadas pelas instituições de diversas instâncias (governos federal, estadual e municipal, bem como a própria escola) e as táticas que os professores utilizam/criam para construir a prática cotidiana, o que, nem sempre, ocorre de forma pacífica. (SCALZER, 2007).

Segundo a autora:

O elemento normatizador (PCN) lhes foi apresentado pelas mãos dos sujeitos externos à escola (MEC e Secretaria de Educação), ou, conforme Chevallard, a noosfera, que havia se encarregado de elaborar o documento agora, em seus níveis locais, apresentou-os àqueles que deveriam executá-lo de modo que eles não tiveram outra possibilidade de ação, senão a da tática. (SCALZER, 2007, p. 140).

Logo, apesar dos PCNs terem sido apresentados ao público docente, no ano de 1997, como uma proposta que desobrigava sua adoção, pode-se observar que, talvez por constituir-se na única proposta formal de que se dispunha naquele momento, ou pela carência de orientação que atinge os docentes, mesmo aqueles que, inicialmente, ofereceram resistência, ou mesmo negaram os PCNs, acabaram por adotá-los em sua prática. Mesmo os que mais tarde os refutaram, novamente, os retomaram e se propuseram a reavaliá-los. (SCALZER, 2007).

Dessa forma, Scalzer (2007) conclui que os docentes de História ressignificaram discursos sobre a realidade imposta, dada a ler: propostas dos Parâmetros. Apropriaram-se somente do que lhes interessava para a sua prática docente, por meio de táticas, que permitiram escolhas baseadas na sua formação e suas reais condições de trabalho no cotidiano escolar, frente a um documento normatizador, produzido na noosfera.

Como podemos observar, nos últimos anos da década de 1980 e no decorrer da década de 1990, houve um movimento de mão dupla em relação às propostas educacionais elaboradas nos estados e municípios e os PCNs, no âmbito nacional: ao mesmo tempo que as propostas educacionais influenciavam na escrita dos PCNs, estes também influenciavam as propostas educacionais em curso.

Embora a pesquisa de Silva (2014), tenha sido selecionada nos critérios de refinamento de nossas buscas bibliográficas, por não abordar o ensino de História nas três últimas décadas do século XX, objeto de nosso estudo, a mesma contribui para evidenciar as continuidades dos PCNs e da organização de programas no âmbito federal, presentes nas orientações curriculares no Espírito Santo, gestadas na década de 1990.

Conforme Silva (2014), o Plano Estadual de Educação, de 1996 a 1999, organizado no então governo de Vitor Buaiz, deixa claro o interesse em se priorizar o ensino médio, ampliando sua acessibilidade para todos. Entretanto, fora desse período, o ensino médio, no estado do Espírito Santo, orientou-se pelos programas e ações elaborados pelo governo federal, não existindo um projeto próprio de educação. Um projeto de educação, contendo orientações curriculares, só foi elaborado e apresentado à sociedade capixaba em 2009, denominado de Currículo Básico Escola Estadual (CBEE).

Os apontamentos de Silva (2014) coadunam com Ferreira (2004), sendo aquela taxativa, no documento "Política Educacional do Estado do Espírito Santo", em relação à Secretaria Estadual de Educação (Sedu), que “[...] vinha implementando projetos do Governo Federal ou de Minas Gerais, sem uma necessária articulação entre eles e, sobretudo, sem uma definição de uma proposta 
pedagógica que pudesse dar organicidade às ações” (ESPÍRITO SANTO, 2004, p. 10). Conforme a autora, o estado deve ter clareza de suas políticas educacionais.

Conforme Silva (2014) o documento Política Educacional do Estado do Espírito e outros elaborados no início dos anos de 2000 apontam ressonância, principalmente, dos PCNs. Mas, podemos inferir, das leituras para nossa pesquisa, que as propostas curriculares elaboradas no processo histórico no Espírito Santo, encontraram resistência em seus destinatários: os professores.

\section{CONSIDERAÇÕES FINAIS}

Ao percorrermos os caminhos da História e seu ensino, no Brasil e no estado do Espírito Santo, nas três últimas décadas do século XX, buscamos identificar mudanças e permanências. Arriscamos a dizer que houve mais permanências do que mudanças. A história do ensino de História como temática de pesquisa só se fez presente, efetivamente, a partir da década de 1980. Verificamos os diferentes momentos e lugares da produção e ressignificação desse ensino. Quase sempre, o lugar da noosfera.

As fases conturbadas em que se inserem as propostas curriculares nos apontam para as disputas e interesses das instituições federais, estaduais e municipais para legitimar determinados conhecimentos a serem trabalhados nas escolas, os quais não foram recebidos sem resistência por aqueles a quem se destinavam: os professores. Foi uma resistência de quem conhece e sabe das dificuldades encontradas em seu cotidiano escolar. Suas vozes encontraram pouco ou nenhuma ressonância nos textos produzidos que chegaram até eles. Cabe ressaltar que resistiram às propostas, mas não as desprezaram - as ressignificaram, conforme condições reais de trabalho.

No decorrer de nossa pesquisa, percebemos que existe uma linha ínfima entre o que foi concebido como Estudos Sociais e o que hoje entendemos como ensino de História e/ou Ârea de Ciências Humanas. As marcas dos Estudos Sociais são perceptíveis nos PCNs, que são apresentados por "áreas de conhecimento", constituindo as denominadas "Ciências humanas e suas tecnologias" e nas propostas curriculares do estado do Espírito Santo, no Currículo Básico Escola Estadual.

Se, por um lado, ao percorrermos os caminhos da História e seu ensino, constatamos os esforços e os impasses para superar a constituição de uma História nacional, unívoca, por uma História que dê espaço e reconheça diferentes sujeitos na sua construção, por outro lado, sem perder de vista o que se conquistou na área, ao longo das últimas décadas do século XX, estamos tendenciosos em concordar com Bittencourt (2004) e Fonseca (1993), que o ensino de História começa com uma "genealogia da nação", e segue caminhando dentro de um processo em que o Estado, ao estender seus tentáculos, em todas as instâncias educacionais, reorganiza e adequa o ensino e a aprendizagem de acordo com seus interesses.

Mas, ao refazer os caminhos percorridos pela História e seu ensino no Espírito Santo, encontramos um alento: a concepção de que ensinar História não é apenas repetir conhecimentos produzidos na noosfera, há também uma produção escolar. Tal concepção se faz presente na resistência apresentada e na narrativa dos professores entrevistados nas teses e dissertações que nos forneceram sustentação teórica. É na sala de aula que a História se transforma.

\section{REFERÊNCIAS}

BITTENCOURT, Circe Maria Fernandes. Identidade Nacional e Ensino de História do Brasil. (p. 185-203). In: KARNAL, Leandro. História na sala de aula: conceitos, práticas e propostas. São Paulo: Contexto, 2010. 
BITTENCOURT, Circe Maria Fernandes. Ensino de história: fundamentos e métodos. São Paulo: Cortez, 2004.

BITTENCOURT, Circe Maria Fernandes. Propostas Curriculares de História: continuidades e transformações. In: BARRETO, Elba Siqueira de Sá (org.). Os currículos do Ensino fundamental para as escolas brasileiras. Campinas: Autores Associados/Fundação Carlos Chagas, 1988.

BITTENCOUT, Circe Maria Fernandes. Abordagens Históricas sobre a História Escolar. Educ. Real. Porto Alegre. v. 36. n. 1. jan./abr. 2011. p. 83-104. Disponível em https://seer.ufrgs.br/educacaoerealidade/article/view/15136. Acesso em 21 set. 2020.

BRASIL. Constituição da República Federativa do Brasil. Brasília, 1988.

BRASIL. LDB. Lei 9394/96 - Lei de Diretrizes e Bases da Educação Nacional. Disponível em www.planalto.gov.br. Acesso em 7 out. 2020.

BRASIL. Ministério da Educação. Parâmetros Curriculares Nacionais (PCNs). História. Ensino Fundamental. Terceiro e quarto ciclos. Brasília: MEC/SEF, 1998.

BRASIL. Ministério da Educação. Parâmetros curriculares nacionais: Ensino Médio. Brasília: MEC/SEMTC, 1997. Disponível em http://portal.mec.gov.br/seb/arquivos/pdf/livro01.pdf. Acesso em 5 out. 2020.

CERTEAU, Michel de. A invenção do cotidiano: - 1. Artes de fazer. 10. ed. Petrópolis: Vozes, 2004.

COSTA, Aryana Lima; OLIVEIRA, Margarida Maria Dias de. O ensino de história como objeto de pesquisa no Brasil: no aniversário de 50 anos de uma área de pesquisa, notícias do que virá. Saeculum - Revista de História [16], João Pessoa, jan./jun. 2007. p. 147-160. Disponível em https://edisciplinas.usp.br/pluginfile.php/858887/mod resource/content/1/2007-

O $\% 20$ Ensino $\% 20$ de $\% 20$ hist $\%$ C $3 \%$ B 3 ria $\% 20$ como $\% 20$ objeto $\% 20 \mathrm{de}^{2} \% 20$ pesquisa $\% 20$ no $\% 20 \mathrm{Bra}$ sil.pdf. Acesso em 20 set. 2020.

CHARTIER, Roger. A História Cultural: entre práticas e representações. Lisboa: Difel, 1990.

ESPÍRITO SANTO (Estado). Secretaria da Educação. Plano Estadual de Educação. Vitória: SEDU, 1995.

FONSECA, Selva Guimarães. Caminhos da história ensinada. São Paulo: Papirus, 1993.

FONSECA, Selva Guimarães. Didática e prática de ensino de História: experiências, reflexões e aprendizados. 13. ed. Campinas, São Paulo: Papirus, 2012.

FRANÇA, Aldaíres Couto. Propostas curriculares para o ensino de estudos sociais: circulação e apropriações de representações de ensino de história e de aperfeiçoamento de professores (Espírito Santo, 1956 - 1976). 2013. 294f. Tese (Doutorado em Educação) - Universidade Federal do Espírito Santo: Vitória, 2013.

Disponível

em http://portais4.ufes.br/posgrad/teses/tese 7250 TEXTO $\% 20$ COMPLETO $\% 20$ TESE $\% 20 D A$ \%20ALDAIRES\%20SOUTO\%20FRAN\%C7A.pdf. Acesso em 10 ago. 2020.

GATTI JR., Décio. Demandas sociais, formação de cidadãos e ensino de história. In: OLIVEIRA, Margarida Maria Dias de (coord.). Brasilia: Ministério da Educação, Secretaria de Educação Básica, v. 21, 2010. (Coleção Explorando o Ensino).

LUIZ, Miriã Lúcia. Dentro e fora da ordem: diretrizes curriculares para o ensino de História em tempos autoritários (1964-1985) 2015. 205f. Tese (Doutorado em Educação) - Universidade Federal do Espírito Santo: Vitória, 2015. Disponível em http://repositorio.ufes.br/bitstream/10/2236/1/tese 8736 TESE $\% 20$ -

\%20MIRI\%c3\%83\%20L\%c3\%9aCIA\%20LUIZ.pdf. Acesso em 8 ago. 2020. 
SCALZER, Jaquelini. Ensino de história e parâmetros curriculares nacionais: do proposto ao efetivado: apropriações e táticas dos professores na elaboração da História ensinada. 2007. 234f. Dissertação. (Mestrado em Educação) - Programa de Pós-Graduação em Educação, Universidade Federal do Espírito Santo, Vitória, 2007.

SILVA, Pedro Pauliano da. A resistência ao currículo de História para o Ensino Médio prescrito pela Secretaria de Estado da Educação do Estado do Espírito Santo. 2014. 174f. Dissertação. (Mestrado em Educação) - Programa de Pós-Graduação em Educação, Universidade Federal do Espírito Santo, Vitória, 2014.

ZAMBONI, Ernesta. Panorama das pesquisas no ensino de História. Saeculum - Revista de História, João Pessoa, Departamento de História da Universidade Federal da Paraíba, n. 6/ 7, jan.-dez. 2000/ 2001, $\quad$ p. $106 . \quad$ Disponível em https://moodle.ufsc.br/pluginfile.php $/ 834355 / \mathrm{mod}$ resource $/$ content $/ 1 /$ Zamboni $\% 20$ \%20Saeculum.pdf. Acesso em 21 set. 2020.

\section{Informações das autoras}

Regina Celi Frechiani Bitte

Universidade Federal do Espírito Santo - UFES

E-mail:bitteregina@gmail.com

ORCID: http://orcid.org/0000-0001-6819-3900

Link Lattes: http://lattes.cnpq.br/8436866512999341

Sonia Maria dos Santos

Universidade Federal de Uberlândia - UFU

E-mail:soniaufu@gmail.com

ORCID: https://orcid.org/0000-0002-7217-1576

Link Lattes: http://lattes.cnpq.br/9281057859793276 